\title{
Correction to: Flint Type Analysis of Bifaces FromAcheulo-Yabrudian Qesem Cave (Israel) Suggestsan Older Acheulian Origin
}

\author{
Aviad Agam $^{1} \cdot$ Lucy Wilson $^{2} \cdot$ Avi Gopher $^{1} \cdot$ Ran Barkai $^{1}$ \\ Published online: 17 December 2019 \\ (C) Springer Nature Switzerland AG 2019
}

\section{Correction to: Journal of Palaeolithic Archaeology https://doi.org/10.1007/s41982-019-00038-0}

The original version of this article unfortunately contained a mistake. The last sentence of the first paragraph of the Introduction section should read "Numbers of handaxes found in Acheulo-Yabrudian contexts vary from a few isolated artefacts (as in Zuttiyeh Cave; see Gisis and Bar-Yosef 1974) to several thousands (as in Tabun Cave; see Shimelmitz et al. 2017)".

\footnotetext{
This article belongs to the Topical Collection: The bifacial shaping phenomenon over time and space
} Guest Editors: Marie-Hélène Moncel and Marta Arzarello

The online version of the original article can be found at https://doi.org/10.1007/s41982-019-00038-0

Aviad Agam

aviadkra@post.tau.ac.il

1 Department of Archaeology and Ancient Near Eastern Cultures, Tel Aviv University, Ramat Aviv, Israel

2 Department of Biological Sciences, University of New Brunswick in Saint John, Saint John, Canada 